\title{
METODE SIMULASI DAN LATIHAN TERHADAP KEMAMPUAN INTERPRETASI PARTOGRAF PADA MAHASISWA KEBIDANAN
}

\author{
${ }^{1}$ Isnina \\ ${ }^{1}$ STIKes Borneo Cendekia Medika Pangkalan Bun \\ ${ }^{1}$ Email : nina_mjk01@yahoo.co.id
}

\begin{abstract}
Abstrak
Partograf pada saat pertolongan persalinan oleh bidan merupakan hal yang sangat penting. Namun dalam praktiknya masih banyak bidan yang tidak mengetahui penggunaan partograf untuk memantau kemajuan persalinan serta tidak mampu menafsirkan temuan partograf sehingga sering kali terlambat mengenali tanda- tanda penyulit pada persalinan dan mengakibatkan kematian pada ibu. Oleh karena itu, calon tenaga kesehatan terutama mahasiswa institusi pendidikan kesehatan perlu dipersiapkan sedini mungkin untuk menguasai dan mengaplikasikan interpretasi partograf. Hal ini diperlukan mengubah model pembelajaran yang tidak hanya berpusat pada guru saja akan tetapi pembelajaran pada siswa seperti simulasi dan latihan. Penelitian ini bertujuan untuk menganalisis metode simulasi dan latihan dengan metode konvensional terhadap kemampuan interpretasi partograf pada mahasiswa kebidanan. Desain penelitian Quasi Experimental dengan rancangan PrePostest With Control Group Design. Subjek penelitian ini adalah seluruh mahasiswa DIII Kebidanan Semester III STIKes Insan Cendekia Medika Jombang sejumlah 50 orang. Data dianalisis dengan Uji Statistik Mann Whitney dan Uji Independent Sample Test,Chi-Square. Hasil Penelitian ini menujukkan terdapat perbedaan yang signifikan antara simulasi dan latihan dengan metode konvensional terhadap peningkatan kemampuan interpretasi partograf mahasiswa kebidanan dengan nilai $\mathrm{p}=$ $<0,05$; RR sebesar 2,60 (IK 95\%=1,09-6,20) menjelaskan metode yang diberikan simulasi dan latihan berpeluang 2,60 kali memiliki kemampuan baik interpretasi partograf dibandingan metode konvensional.
\end{abstract}

Kata Kunci : Simulasi dan Latihan, Kemampuan, Interpretasi Partograf.

\section{SIMULATION AND EXERCISE METHOD OF ABILITY PARTOGRAPH INTERPRETATION OF MIDWIFE STUDENTS}

\begin{abstract}
Partographs during delivery assistance by midwives are very important. However, in practice there are still many midwives who do not know the use of partographs to monitor the progress of labor and are unable to interpret the findings of partographs and are often late in recognizing signs of complications in labor and resulting in maternal death. Therefore, prospective health workers, especially students of health education institutions need to be prepared as early as possible to master and apply partograph interpretations. This is necessary to change the learning model that is
\end{abstract}


not only teacher centered but also student learning such as simulations and exercises. This study aims to analyze simulation methods and exercises with conventional methods for the ability to interpret partographs in midwifery students. Quasi Experimental research design with a Pre-Postest With Control Group Design. The subjects of this study were all 50 Midwifery III Semester III students of Insik Scholar Medicines in Jombang. Data were analyzed with the Mann Whitney Statistical Test and the Independent Sample Test, Chi-Square. The results of this study show there are significant differences between simulations and exercises with conventional methods to increase the ability of interpreting partograph of midwifery students with $p=\langle 0.05$; RR of 2.60 (95\% CI = 1.09-6.20) explains the method given simulation and 2.60 times the opportunity to have a good ability to interpret partographs compared to conventional methods.

Keywords: Simulation and Exercise, Ability, Partograph Interpretation.

\section{PENDAHULUAN}

Bidan sebagai salah satu tenaga kesehatan yang berperan dalam pencapaian Universal Health Coverage 2019 harus di didik dalam suasana proses pembelajaran yang mampu menggali potensi dirinya baik Hard Skills ataupun Soft Skills dalam penguasaan kompetensi yang harus dimilikinya. ${ }^{1}$ Banyaknya jumlah institusi pendidikan kebidanan menjadikan kualitas lulusannya tidak merata dan belum memberikan kontribusi yang cukup baik terhadap target $M D G$ 's yaitu menurunkan angka kematian ibu dan bayi di Indonesia. Kematian ibu dan bayi merupakan masalah yang sulit untuk ditanggulangi meskipun perkembangan teknologi dibidang kesehatan sudah semakin berkembang.

Sesuai dengan standar pertolongan persalinan bidan wajib melakukan pengisian partograf. Begitu pula bila penolong persalinan adalah mahasiswa kebidanan juga berkewajiban untuk membuat mengisi partograf. Namun dalam praktiknya, masih banyak bidan yang tidak menggunakan partograf untuk memantau kemajuan persalinan atau persepsi keliru dalam mengisi partograf serta tidak mampu menafsirkan temuan partograf sehingga sering kali terlambat mengenali tandatanda penyulit pada persalinan dan mengakibatkan kematian pada Ibu. ${ }^{5}$ Oleh karena itu diperlukan salah satu alasan penggunaan partograf oleh bidan untuk menegakkan diagnosa awal/interpretasi persalinan tepat waktu serta tepat melaksanakan rujukan.

Dalam pencapaian pertolongan persalinan yang dibuat mahasiswa pendidikan bidan masih banyak ditemukan menafsirkan temuan dipartograf yang kurang tepat. Oleh karena itu, calon tenaga kesehatan terutama mahasiswa institusi pendidikan kesehatan perlu dipersiapkan sedini mungkin untuk menguasai dan mengaplikasikan interpretasi partograf. Mahasiswa butuh pengalaman praktik yang tepat, benar dan baik sehingga dapat mencapai kompetensi bidan dengan baik. ${ }^{6}$ Salah satu upaya yang dapat dilakukan untuk menyelesaikan permasalahan tersebut adalah dengan meningkatkan kualitas sistem pendidikan yang sesuai dengan kebutuhan masyarakat. Oleh karena itu perlu model pembelajaran yang mampu mengintegrasikan bidang- bidang ilmu yang dibutuhkan lulusan bidan untuk 
memenuhi kebutuhan masyarakat secara menyeluruh dan utuh. ${ }^{7}$ Metode simulasi dan latihan mungkin akan lebih baik jika diterapkan para dosen dalam proses belajar mengajar, khususnya tentang interpretasi partograf karena mahasiswa lebih berperan aktif dan berlatih peran untuk memahami suatu konsep atau keterampilan, dengan mengubah model pembelajaran yang tidak hanya berpusat pada guru atau pengajar saja akan tetapi pembelajaran pada siswa.

Metode pembelajaran simulasi dan latihan merupakan salah satu pembelajaran menggunakan situasi tiruan dan pembelajaran secara kelompok. pembelajaran simulasi dan latihan dapat meningkatkan prestasi belajar mahasiswa sekaligus dapat meningkatkan kemampuan hubungan sosial dan dapat merealisasikan kebutuhan siswa dalam belajar berpikir, memecahkan masalah dan mengintegrasikan pengetahuan dan keterampilan. $^{8} \quad$ Mahasiswa menggunakan metode simulasi dan latihan dengan melakukan tingkah laku tiruan maka mahasiswa melatih keterampilan dan keaktifan belajar yaitu, dalam Interpretasi partograf. Adapun tujuan dari penelitian ini adalah untuk menganalisis metode simulasi dan latihan dengan metode konvensional terhadap kemampuan interpretasi partograf pada mahasiswa kebidanan.

\section{METODE PENELITIAN}

Rancangan penelitian yang digunakan adalah penelitian kuantitatif dengan pendekatan studi eksperimen semu, pretest posttest with control group design. Penelitian dilakukan di Program Studi DIII Kebidanan STIKes Insan Cendekia Medika Jombang pada
Bulan Oktober 2016 - Januari 2017 atau pada saat semester ganjil tahun akademik 2016/2017 berjalan. Populasi dalam penelitian ini adalah seluruh mahasiswa STIKes Insan Cendekia Medika Jombang, dengan populasi terjangkau yaitu mahasiswa tingkat II semester III program studi diploma tiga kebidanan STIKes Insan Cendekia Medika Jombang. Sampel dalam penelitian ini adalah mahasiswa program studi diploma tiga kebidanan STIKes Insan Cendekia Medika Jombang yang memenuhi kriteria inklusi dengan teknik pengambilan sampel secara total sampling, sehingga jumlah sampel yang memenuhi kriteria inklusi adalah 50 orang terdiri dari dua kelas, yaitu kelas A $(\mathrm{n}=25)$ dan kelas $B$ $(n=25)$. Kriteria inklusi pemilihan sampel antara lain responden merupakan mahasiswa semester III reguler tingkat II program studi kebidanan STIKes Insan Cendekia Medika Jombang yang aktif pada semester ganjil tahun akademik 2016/2017, mahasiswa yang mengikuti yang mengikuti mata kuliah asuhan kebidanan persalinan, mengikuti pembelajaran dilaboratorium.

Adapun kriteria eksklusi antara lain mahasiswa yang tidak bisa hadir (sakit, izin, tanpa keterangan) pada saat penentuan sampel. Setiap responden diminta persetujuannya untuk mengikuti penelitian dengan menandatangani lembar informed consent. Prosedur penelitian yaitu peneliti membagi sampel penelitian (mahasiswa) dalam dua kelompok, kelompok A (kelas A) sebagai kelas dengan metode simulasi dan latihan dan kelompok B (kelas B) sebagai kelas dengan metode konvensional. Sebelum melaksanakan metode pembelajaran pada kedua kelompok, dilakukan pretest kemampuan ( pengetahuan, sikap, keterampilan) 
Interpretasi partograf. Kemudian setelah satu bulan akan dilaksanakan posttest yang akan mengukur kemampuan (pengetahuan, sikap dan keterampilan) interpretasi partograf pada kelompok intervensi dan kelompok kontrol.

Data yang digunakan dalam penelitian ini adalah data primer dan data sekunder. Untuk data primer, menggunakan kuesioner yang berupa soal pilihan ganda untuk mengukur kemampuan pengetahuan, pengukuran sikap menggunakan kuesioner dengan skala Likert dan pengukuran keterampilan dengan daftar tilik. Data sekunder berupa nilai indeks prestasi mahasiswa. Kuesioner yang digunakan adalah kuesioner yang telah diuji validitas dan reliabilitasnya. Data yang telah dikumpulkan kemudian diolah dan dianalisis secara univariabel dan bivariabel dengan bantuan program SPSS ver.20. Analisis univariabel dilakukan menggunakan statsistik deskriptif untuk menggambarkan kemampuan interpretasi partograf setelah metode simulasi dan latihan diterapkan. Untuk data kategorik dilakukan perhitungan jumlah dan persentase, sedangkan tiap variabel dilakukan perhitungan mean, median, standar deviasi dan rentang. Analisis bivariabel untuk menguji hipotesis komparatif kedua sampel. Karena data tidak terdistribusi normal, maka uji yang digunakan adalah uji non parametric yaitu uji Wilcoxon untuk menganalisis perbedaan kemampuan interpretasi partograf pada kedua kelompok.

Uji Mann Whitney dan uji independent t-test untuk menganalisis perbedaan rerata nilai kemampuan interpretasi partograf antara kedua kelompok dan uji chi-square menganalisis perbedaan pengaruh simulasi dan latihan dengan metode konvensional terhadap kemampuan interpretasi partograf.

\section{HASIL PENELITIAN}

Analisis perbedaan skor awal (pre test) dan skor akhir (post test) bertujuan untuk mengetahui kebermaknaan perbedaan peningkatan skor pre test dan post test pada kedua kelompok metode pembelajaran. Adapun perbedaan skor kemampuan (pengetahuan, sikap, dan keterampilan) interpretasi partograf pada kedua kelompok metode pembelajaran disajikan pada tabel berikut

Tabel 1 Perbedaan Skor Peningkatan kemampuan Interpretasi partograf Pada Kelompok Simulasi dan Latihan dengan Kelompok Konvensioanl (Pre dan Post)

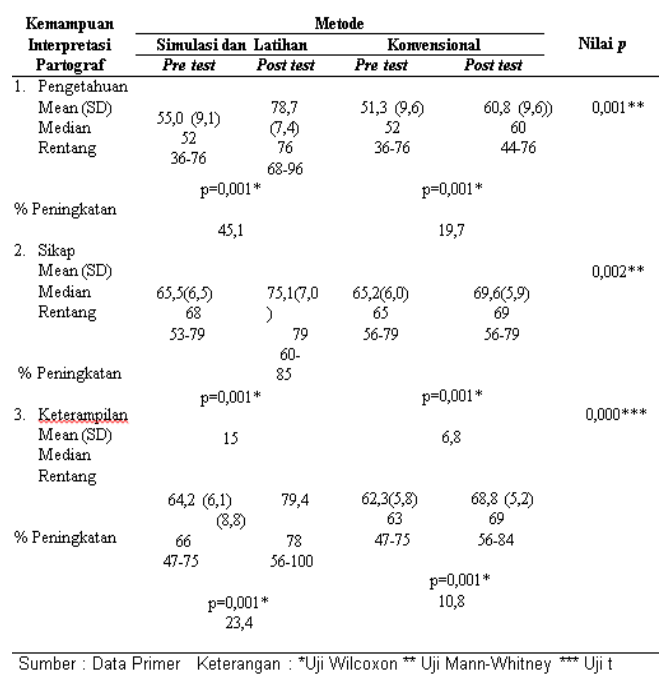

Berdasarkan hasil penelitian yang terdapat pada tabel 1 diatas, menujukkan perbedaan yang bermakna terhadap kemampuan (pengetahuan,sikap, keterampilan) interpretasi partograf sebelum dan sesudah intervensi pada kelompok 
perlakuan dan kelompok kontrol dengan nilai $\mathrm{p}=0,001$ dan didapatkan rata-rata peningkatan kemampuan (pengetahuan dan Sikap) dengan menggunakan uji statistik MannWhitney dan keterampilan menggunakan uji statistik Independent Samples Test diperoleh nilai $\mathrm{p}<0,05$ yang artinya terdapat perbedaan yang bermakna antara kelompok perlakuan (simulasi dan latihan) dan kelompok kontrol konvensional. Terbukti bahwa peningkatan skor pengetahuan sebesar $45,1 \%$, sikap $15 \%$ dan keterampilan $23,4 \%$ pada kelompok perlakuan Sedangkan pada kelompok kontrol peningkatan skor pengetahuan 19,7 \%, sikap $6,8 \%$ dan keterampilan 10,8\%.

\section{Tabel 2 Perbedaan Pengaruh Kelompok Simulasi dan Latihan dengan Kelompok Konvensioanl terhadap Peningkatan Kemampuan Interpretasi Partograf}

\begin{tabular}{ccc}
\hline \multirow{2}{*}{ Kelompok } & \multicolumn{2}{c}{ Variabel } \\
\cline { 2 - 3 } & \multicolumn{2}{c}{ Kemampuan Interpretasi Partograf } \\
\cline { 2 - 3 } Berlakuan & $13(52 \%)$ & $12(48 \%)$ \\
Kontrol & $5(20 \%)$ & $20(80 \%)$ \\
& \multicolumn{2}{c}{ Kurang Baik } \\
\hline Nilai p $^{*}$ & \multicolumn{2}{c}{$\mathbf{0 1 8}$} \\
\hline RR (IK 95\%) & \multicolumn{2}{c}{$\mathbf{2 , 6 0}(\mathbf{1 , 0 9 - 6 , 2 0 )}$}
\end{tabular}

Sumber Data Primer Keterangan :* Uji ChiSquare

Tabel 2 menunjukkan hasil bahwa pada kelompok perlakuan terdapat 13 $(52 \%)$ mahasiswa yang mengalami peningkatan kemampuan baik interpretasi partograf dibandingkan dengan kelompok kontrol yang hanya 5 (20\%) mahasiswa. Pada tabel tersebut juga menunjukkan hasil bahwa terdapat perbedaan pengaruh simulasi dan latihan terhadap kemampuan interpretasi partograf.
Berdasarkan uji statistik menggunakan Chi-Square test pada kemampuan interpretasi partograf nilai $\mathrm{p}<0,05$ dengan RR 2,60 IK 95\% Artinya kelompok yang diberikan simulasi dan latihan berpeluang 2,60 kali memiliki kemampuan baik interpretasi partograf dibandingkan kelompok konvensional.

\section{PEMBAHASAN}

Penilaian Kemampuan pengetahuan harus diikuti dengan penilaian sikap dan keterampilan, sesuai pendapat Carl Rogers dalam Muslich yang menyatakan bahwa kemampuan mahasiswa menguasai tingkat pengetahuan tertentu maka dapat diramalkan sikap dan keterampilannya. Pengetahuan memiliki hubungan dengan perbuatan berupa sikap dan keterampilan, karena pada hakikatnya perbuatan seseorang berasal dari struktur pengetahuan. ${ }^{9} \quad$ Penilaian terhadap hasil belajar kemampuan interpretasi partograf harus memenuhi kompetensi yang terdiri dari tiga ranah yaitu pengetahuan, sikap, dan keterampilan. Berdasarkan hasil penelitian ada perbedaan yang bermakna antara kelompok perlakuan dan kelompok kontrol pada peningkatan skor kemampuan pengetahuan interpretasi partograf dengan nilai $\mathrm{p}<0,05$. Hal ini berarti penggalian pengetahuan atau penyampaian informasi mengenai partograf lebih mendalam pada kelompok yang mendapatkan metode simulasi dan latihan dibandingkan dengan metode konvensional. Hasil penelitian ini sesuai dengan hasil penelitian dalam American Journal of Pharmaceutical Education yang dinyatakan bahwa terdapat peningkatan yang signifikan skor 
pertanyaan posttest setelah diberi simulasi dan latihan. ${ }^{10}$

Selain mempengaruhi peningkatan skor pengetahuan interpretasi partograf juga mempengaruhi sikap. Hal ini sesuai dengan table 1 didapatkan ada perbedaan yang bermakna antara kelompok perlakuan dan kelompok kontrol pada peningkatan skor sikap dengan nilai $\mathrm{p}<0,05$. Hal ini terbukti peningkatan skor sikap lebih tinggi pada kelompok perlakuan yaitu $15 \%$ sedangkan pada kelompok kontrol hanya $6,8 \%$.

Hal ini berarti perlakuan berupa simulasi dan latihan memiliki pengaruh/dampak terhadap sikap mahasiswa mengenai interpretasi partograf. Hal ini sesuai dengan teori yang menyatakan bahwa sikap akan bergantung pada sejauh mana komunikasi/sugesti/informasi itu diperhatikan, dipahami, dan diterima. ${ }^{11}$ Hasil dari penelitian Koponen menyatakan bahwa peningkatan sikap yang positif dari kelompok yang mendapatkan metode simulasi lebih tinggi dibandingkan dengan bermain peran. ${ }^{12}$ Pada metode simulasi dan latihan mahasiswa melakukan keterampilan interpretasi partograf membuat situasi seperti nyata dan belajar aktif secara individu. Hal ini sesuai dengan hasil penelitian yang dinyatakan bahwa simulasi meyediakan realisme tingkat tinggi dan memiliki potensi yang efektif melatih keterampilan. Hal ini terbukti dari hasil penelitian pada tabel 1 skor kemampuan keterampilan antara kelompok perlakuan dan kelompok kontrol terdapat perbedaan yang bermakna dengan nilai $\mathrm{p}<0,05$. Hal tersebut juga sesuai dengan hasil penelitian dalam American Journal of Pharmaceutical Education dinyatakan bahwa simulasi memberikan umpan balik yang membuat mahasiswa dapat meningkatkan keterampilannya. Hasil penelitian Bray dkk bahwa kegiatan simulasi dan latihan memberikan keuntungan bagi mahahiswa untuk mempraktikkan keterampilan mereka dapat mengintergrasikan pengetahuan, komunikasi, profesionalisme, dan aplikasi klinis. ${ }^{13}$

Berdasarkan hasil penelitian tabel 2 Kemampuan Interpretasi Partograf antara kelompok perlakuan dan kelompok kontrol terdapat perbedaan yang bermakna dengan nilai $\mathrm{p}<0,05$. Hal ini terbukti pada kelompok perlakuan terdapat $13 \quad(52 \%)$ mahasiswa yang mengalami peningkatan kemampuan baik interpretasi partograf dibandingkan dengan kelompok kontrol yang hanya 5 (20\%) mahasiswa. Sebanyak 12 mahasiswa (48\%) pada kelompok perlakuan memiliki kemampuan kurang baik interpretasi partograf walaupun telah diberikan metode simulasi dan latihan, hal ini bisa dikarenakan masih adanya mahasiswa yang kurang aktif dalam proses pembelajaran.

Kemungkinan mahasiswa tersebut kurang pemahaman, kurang berlatih dalam mengisi partograf dan interpretasi partograf sehingga mempengaruhi keterampilan dan kemampuan mereka dalam interpretasi partograf serta pada waktu pembelajaran simulasi dan latihan kurangnya pengalaman keterampilan atau penguasaan mahasiswa terhadap masalah sosial yang diperankan. Jika dibandingkan dengan kelompok kontrol mahasiswa yang kemampuan kurang baik interpretasi partograf sebanyak 20 mahasiswa (80\%) lebih tinggi dibandingkan mahasiswa yang kemampuan kurang baik interpretasi partograf pada kelompok perlakuan. 
Hal ini juga didukung dengan uji statistik Chi-Square RR 2,60 IK 95\%, artinya kelompok yang diberikan simulasi dan latihan berpeluang 2,60 kali memiliki kemampuan baik interpretasi partograf dibandingkan kelompok konvensional.

Hal ini didukung oleh penelitian Ismail yang mengatakan bahwa simulasi dan latihan pembelajaran yang dapat mengkorelasikan materi yang ditemukan dengan kehidupan nyata serta mampu menumbuhkan penguatan konsep kepada mahasiswa dan meyelesaikan masalah, mengembangkan pengetahuan dan keterampilan dalam memecahkan masalah serta memacu keaktifan mahasiswa. ${ }^{14}$ Hal ini sesuai dengan teori dari Sudjana yang mengatakan bahwa strategi pengajaran yang tepat akan menghasilkan hasil belajar yang lebih baik.

Pembelajaran dengan simulasi dan latihan bertujuan untuk menerapkan pengetahuan, keterampilan, serta sikap yang telah diperoleh sebelumnya dalam suatu situasi yang dirancang seperti melakukan manajemen pada pasien nyata. Selain itu, penggunaan metode simulasi dan latihan ini untuk memberikan pengalaman kepada mahasiswa dalam mengelola masalah yang terjadi pada pasien terutama dalam situasi darurat. Saat penerapan simulasi dan latihan digunakan agar mendekati lingkungan atau kondisi nyata. Hal ini untuk memberikan kesempatan kepada mahasiswa melakukan keterampilan praktik dalam situasi yang dirancang seperti nyata. ${ }^{15}$

Menurut Penelitian Murphy dkk bahwa melalui pembelajaran simulasi dan latihan mahasiswa diberi peran masingmasing yang dihadapkan pada situasi mirip dengan kondisi nyata, mempraktikkan kemampuan tim, dan berpartisipasi aktif dalam pengambilan keputusan sesuai kasus. ${ }^{16}$ Hal ini kemungkinan ada keterkaitan dengan sikap mahasiswa selama melakukan tindakan keterampilan dan hasil belajar pengetahuan mahasiswa pada tingkat evaluasi. Menurut Muslich menyatakan hasil belajar pengetahuan berdasarkan tingkatannya masing-masing tidak bisa berdiri sendiri, tetapi selalu berhubungan dengan sikap dan keterampilan. Mahasiswa yang berubah tingkat pengetahuannya dalam kadar tertentu, maka sebenarnya sikap dan keterampilan pun berubah. Berdasarkan hasil penelitian tersebut secara umum terdapat perbedaan peningkatan kemampuan (pengetahuan, sikap keterampilan) interpretasi partograf dimungkinkan karena simulasi dan latihan dengan melakukan tingkah laku secara tiruan yang tujuannya untuk memperoleh pemahaman, keterampilan tentang suatu konsep dan dapat juga memecahkan masalah yang bersumber dari keadaan yang sebenarnya serta untuk melatih keterampilan tertentu,memperoleh pemahaman, latihan memecahkan masalah, meningkatkan keaktifan belajar, memberi motivasi mahasiswa dalam belajar serta melatih mahasiswa bekerjasama dalam kelompok dan pada akhirnya akan berpengaruh terhadap hasil belajarnya.

\section{KESIMPULAN DAN SARAN Kesimpulan}

Berdasarkan hasil penelitian tersebut maka disimpulkan bahwa terdapat perbedaan yang bermakna metode simulasi dan latihan dengan metode konvesional terhadap peningkatan kemampuan interpretasi partograf pada mahasiswa kebidanan.

\section{Saran}

Diharapkan ada penelitian lebih lanjut penerapan metode pembelajaran perlu 
melibatkan pasien sebenarnya atau pasien simulasi dan dilakukan lebih lama untuk menganalisis kemampuan seutuhnya selama pelaksanaan metode. Bagi Institusi Penggunaan metode simulasi dan latihan dapat digunakan sebagai alternatif untuk pembelajaran materi partograf serta materi lain pada program D-III kebidanan serta dapat digunakan sebagai strategi pembelajaran untuk menciptakan kondisi lingkungan belajar yang kondusif sehingga mahasiswa dapat termotivasi dalam belajar dan akhirnya hasil belajar pada mahasiswa akan lebih baik.

\section{DAFTAR PUSTAKA}

Yulizawati Y, Rismawanti V. Pengaruh Model Pembelajaran Kooperatif type STAD terhadap Keterampilan Pengisian Partograf Mahasiswa kebidanan. The Southeast Asian Journal of Midwifery. 2016; 1 (1):39-42

Bakti Husada Rencana Pengembangan Tenaga Kesehatan. Rencana Pengembangan Tenaga Kesehatan 2011.

Badan PPSDM. Kesehatan Kementerian Kesehatan Republik Indonesia 2011.

Maryam S. Peran Bidan yang Kompeten terhadap suksesnya $M D G$,s Jakarta: Salemba Medika; 2012. 35-7.

Kartini F. Pengisian Partograf di Bidan Praktik Swasta. Media ilmu Kesehatan. 2013; 2(1) :10-5

Yulia D.W. Hubungan Tingkat Pengetahuan Mahasiswa tentang Partograf dengan Praktik Pengisian Partograf pada Mahasiswa DIV bidan pendidikan semester IV di STIKes Yogyakarta.2014

WHO. Strengthening Midwifery Toolkit : Module 4 Midwifery Practice. 2011

Mulati T, Rejeki AS. Perbedaan Pengaruh Metode Pembelajaran Simulasi dengan Latihan (drill) terhadap penerapan pengisian partograf pada Mahasiswa DIII Kebidanan. Jurnal Cakrawala Pendidikan. 2014; 1 (1).

Muslich. M. Penilaian Berbasis Kelas dan Kompetensi. Bandung : PT Refika Aditama.2011;(1):3350,98

Nancy M, Tofil. Use of Simulation to Enhance Learning in a Pediatric Elective. American Journal of Pharmaceutical Education 2010.

Azwar.S. Sikap Manusia. Yogyakarta : Pustaka Pelajar; 2013

Koponen J. Comparing three experiential learning methods and their effect on medical student's attitudes to learning communication skill. Medical Teacher.2012;34.e198-e207.

Bray Bs, Schwartz Cr, Odegard Ps, Hammer Dp, Seybert Al. Assessment of human patient simulation-based learning. American journal of pharmaceutical education. 2011; 75 (10):208.

Marzuki I. Pengaruh Metode Simulasi terhadap Motivasi dan Hasil belajar siswa. Jurnal ilmiah IKIP Mataram. 2015;2(1).

Akaike M, Nagamune M, Fujimoto A, Tsuji A. Simulation based medical education in clinicall skill laboratory. The Journal of 
Medical

Investigation.2012;(1,2)59

Murphy S,Hartigan I,Walshe N,Flynn

A.V,O'Brien.Merging Problem

Based Learning and Simulation

as Innovative Pedagogy in Nurse

Education.Ireland:University

College Cork; Catherine McAuley

School pf Nirsing and

Midwifery.Elseiver;2010 